\title{
Optimization of rhizogenesis in oil palm (Elaeis guineensis Jacq.) vitro plantlets derived from direct organogenesis of mature zygotic embryos (MZE)
}

\begin{abstract}
Efficiency of auxin to induce and improve root development on in vitro oil palm plantlets obtained from direct organogenesis of mature zygotic embryos (MZE) was assessed. Three auxin types; Indole acetic acid (IAA), Indole butyric acid (IBA) and Naphthalene acetic acid (NAA) were supplemented in Murashige and Skoog (MS) medium in three concentrations $\left(0.5,1\right.$, and $\left.1.5 \mathrm{mgL}^{-1}\right)$. Root development parameters like root induction in micro shoots, increase in root length and proliferation of root hairs in the in vitro plantlets were assessed 30 days after inoculation. Amongst the three auxins, IBA at $1.5 \mathrm{mg} \mathrm{L}^{-1}$ gave best results in root induction $(50 \%)$, root elongation $(4.1 \mathrm{~cm})$ and profuse root hair production while IAA did not show any improvement in all the parameters assessed. Results obtained revealed that better root development in in vitro oil palm plantlets could be obtained in MS medium supplemented with IBA at $1.5 \mathrm{mg} \mathrm{L}^{-1}$.
\end{abstract}

Keywords: IAA, IBA, NAA, Oil palm seedling, rhizogenesis, in vitro plantlets

\author{
Volume 8 Issue 3 - 2018
}

\author{
Tabi Mbi Kingsley, ${ }^{1,2}$ Ntsomboh Ntsefong \\ Godswill, ${ }^{1,2}$ Tonfack Libert Brice, ${ }^{1,4}$ Ngando \\ Ebongue Georges Frank, ${ }^{2}$ and Emmanuel \\ Youmbi ${ }^{1,3}$ \\ 'Department of Plant Biology, Faculty of Science, University of \\ Yaounde, Cameroon \\ ${ }^{2}$ Institute of Agricultural Research for Development (IRAD)- \\ Specialized Centre for Oil Palm Research (CEREPAH), \\ Cameroon \\ ${ }^{3}$ Tissue Culture Laboratory,African Centre for Research on \\ Banana and Plantain (CARBAP), Cameroon \\ ${ }^{4}$ Department of Genetics, Forestry and Agricultural \\ Biotechnology Institute (FABI), University of Pretoria, South \\ Africa
}

Correspondence: Emmanuel Youmbi, Department of Plant Biology, Faculty of Science, University of Yaounde I, P.O. Box 812, Yaounde, Cameroon.

Received: March 12, 2018| Published: May 07, 2018
Abbreviations: IAA, Indole acetic acid; IBA, Indole butyric acid; NAA, Naphthalene acetic acid; MS, Murashige and Skoog; MZE, mature zygotic embryo

\section{Introduction}

Planting of improved seedlings could be a sustainable solution as far as the ever increasing demand for oil palm products is concerned. The production and distribution of elite planting stock of oil palm by the conventional method is hampered by slow and low germination rates due to intensive dormancy. ${ }^{1}$ Besides, oil palm clones produced from somatic embryogenesis to salvage seeding shortage often show undesirable somaclonal variations resulting in abnormalities associated with parthenocarpic fruit set and bunch failure. ${ }^{2}$ This project was initiated to verify the potential of direct organogenesis of mature zygotic embryo (MZE) as an alternative approach for rapid production of oil palm seedlings. In the initial experiment, the rate of direct regeneration of vitro plantlets from MZE of some tenera elites in Cameroon was tested in hormone free Murashige and Skoog (MS) culture medium and results showed a plantlet regeneration rate of 90 $\%$. Unfortunately $70 \%$ of regenerated plantlets did not differentiate completely i.e. in vitro plantlets obtained had only a shoot axis while the root axis was completely absent (Figure 1A). The main challenge noticed in direct organogenesis of MZE was low rhizogenesis. It was impossible for the regenerated plantlets without roots axes to be transferred into the soil pots for hardening and acclimatization. It was within this backdrop that the present study was initiated with the objective to improve rhizogenesis in vitro in oil palm plantlets during direct organogenesis from mature zygotic embryo.

\section{Materials and methods}

Three auxin types: Indole-3-acetic acid (IAA), Indole-3-butyric acid (IBA) and 1-Naphthalene acetic acid (NAA) all supplied by sigma-Aldrich were used as the plant growth regulator to induce rhizogenesis. For each auxin type, three different concentrations were prepared under aseptic conditions and supplemented in full strength MS medium (Table 1). Two main explants types were used. Type lexplants constituted in vitro plantlets that differentiated partially to give a shoot axis only (Figure 1A) while Type 2 comprised of in vitro plantlets that showed complete differentiation into a shoot and a root axis (Figure 1B). Only healthy and robust in vitro plantlets from each explants type were used for rhizogenesis studies. Full MS media supplemented with each of the three auxin types at the three different concentrations were prepared (Table 1). In each culture medium, two randomly selected explants from Type 1 and Type 2 in vitro plantlets were inoculated in three repetitions. In all, the experimental design was completely randomized ( $3 \times 3 \times 2 \times 3$ factorial) including 3 auxin types, 3 concentrations for each type of auxin, 2 types of explants and 3 repetitions for each growth medium. The experiment was incubated at a temperature of $26 \pm 2^{\circ} \mathrm{C}$ under a $16 / 8$ hours photo period, and after a period of 40 days, the rate of root initiation was assessed for explants of Type 1 while root elongation and development of root hairs was evaluated for Type 2 explants. Elongation was done using a graduated graph paper. Statistical analysis was carried out using analysis of variance (ANOVA) and differences among treatment mean were compared using the least significant difference (LSD). 
Table I concentrations of auxin added in the different rooting media

\begin{tabular}{ll}
\hline Auxin type & Medium composition \\
\hline IAA & $M S+0.5 \mathrm{mgL}^{-1}$ \\
& $M S+1 \mathrm{mgL}^{-1}$ \\
& $M S+1.5 \mathrm{mgL}^{-1}$ \\
& $M S+0.5 \mathrm{mgL}^{-1}$ \\
IBA & $M S+1 \mathrm{mgL} L^{-1}$ \\
& $M S+1.5 \mathrm{mgL}^{-1}$ \\
& $M S+0.5 \mathrm{mgL}^{-1}$ \\
NAA & $M S+1 \mathrm{mgL}^{-1}$ \\
& $M S+1.5 \mathrm{mgL}^{-1}$ \\
\hline
\end{tabular}

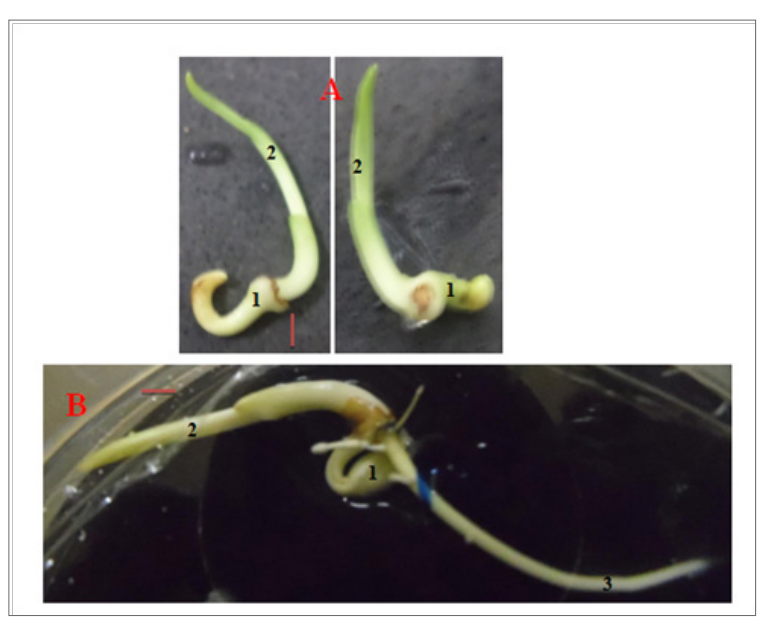

Figure I Explants.

A. In vitro plantlet whose differentiation resulted into a shoot bud only (Type 1 explants);

B. B. In vitro plantlet with complete differentiation in to a root and a shoot bud (Type 2 explants).

1) Remnants of haustorium ;

2) Shoot bud ;

3) Primary horizontal root ; Bar $=5 \mathrm{~mm}$

\section{Results}

The complete absence of a root axis (Figure 1A) for over $70 \%$ of differentiated MZE was observed to be a major constraint in the production of in vitro oil palm plantlets via direct organogenesis of MZE. Roots induction in Type 1 explants (Figure 1A) as well as the growth of roots in Type 2 explants (Figure 1B) was highly influenced by the type and concentration of auxin supplement in full MS medium. In all culture media that received IAA and NAA, no root induction was observed (Figure 2A) within the study period as in the controls where no auxin was added. Out of the three types of auxins employed, only IBA let to roots induction (Figure 2B) in Type 1 explants. However, significant differences were observed in rate of root induction among the different concentrations of IBA. Root induction scores of $50 \%$, $25 \%$ and $0 \%$ were recorded in MS medium supplemented with 1.5 $\mathrm{mg} \mathrm{L}^{-1}, 1 \mathrm{mg} \mathrm{L}^{-1}$ and $0.5 \mathrm{mg} \mathrm{L}^{-1}$ respectively (Table 2). The emerged roots were healthy, robust and contained many secondary roots as well (Figure 2B). As far as growth and development of roots (Figure 2C) in plantlets derived from Type 2 explants is concerned, no increase in root length was observed in explants inoculated in the control and IAA supplemented media. On the other hand, NAA at concentrations of 1.0 and $1.5 \mathrm{mg} \mathrm{L}^{-1}$ showed an average increase of $5 \%$ in initial length. The samples inoculated in $1.5 \mathrm{mg} \mathrm{L}^{-1}$ IBA showed a significant increase of $100 \%$ over their initial length (Table 2). Similarly, the rate of proliferation of root hairs was more profuse in $1.5 \mathrm{mg} \mathrm{L}^{-1}$ IBA compared to other auxins regardless of the concentrations. No root hair development was observed in the control and culture media supplemented with IAA.

Table 2 Effect of auxin types on root induction and development of vitro plantlets

\begin{tabular}{|c|c|c|c|c|c|c|c|c|c|c|}
\hline & \multirow{2}{*}{$\begin{array}{l}\text { Control } \\
0\end{array}$} & \multicolumn{3}{|c|}{ IAA } & \multicolumn{3}{|c|}{ IBA } & \multicolumn{3}{|c|}{ NAA } \\
\hline & & 1 & 2 & 3 & 4 & 5 & 6 & 7 & 8 & 9 \\
\hline \multicolumn{11}{|c|}{$\begin{array}{l}\text { Shoots } \\
\text { (Lotl) that } \\
\text { rooted (\%) }\end{array}$} \\
\hline & 0 & 0 & 0 & 0 & 0 & 16 & 50 & 0 & 0 & 0 \\
\hline \multicolumn{11}{|c|}{$\begin{array}{l}\text { Mean increase in initial } \\
\text { length (\%) for Lot } 2\end{array}$} \\
\hline & 0 & 0 & 0 & 0 & 10 & 25 & 100 & 0 & 10 & 10 \\
\hline \multicolumn{11}{|c|}{$\begin{array}{l}\text { Proliferation } \\
\text { of root } \\
\text { hairs for } \\
\text { Lot } 2\end{array}$} \\
\hline & 0 & 0 & 0 & 0 & $\begin{array}{l}+ \\
+\end{array}$ & $\begin{array}{l}+ \\
+ \\
+\end{array}$ & $\begin{array}{l}++ \\
++ \\
+\end{array}$ & + & + & $\begin{array}{l}+ \\
+\end{array}$ \\
\hline
\end{tabular}

Numbers 0-9 represent different experiments

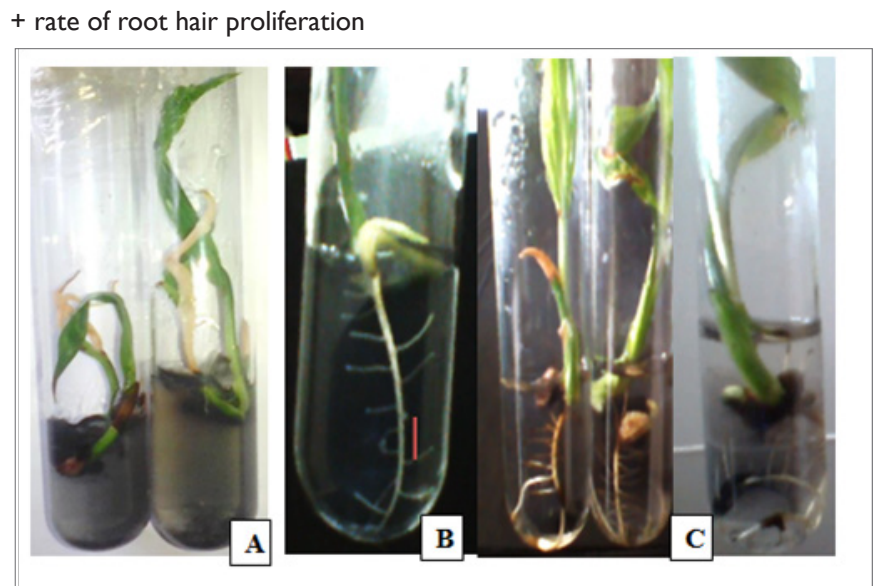

Figure 2 Rhizogenesis response of Types I and 2 explants to auxin:

A. Failure to induce roots in Lot I:

B. Induction of roots from Type I explants (notice the complete whitish nature of the root);

C. Elongation of roots in Type 2 explants (notice the brownish colour of the upper part and the whitish colour of the lower part of the roots).

Bar $=1 \mathrm{~cm}$. In the course of acclimatization, a survival rate of $66.7 \%$ was achieved. When plantlets were transferred in polybags with natural soil, the survival rate was $74.1 \%$. These plantlets were subsequently planted in an experimental field to record their growth parameters, flowers and fresh fruits bunch production. 


\section{Discussion}

The inability to induce adventitious root is often a limiting factor in conventional cuttings and tissue culture. ${ }^{3}$ It is well known that exogenously applied natural or synthetic auxins favors rooting, and there is evidence that this hormone is the most effective inducer of the process. ${ }^{4}$ In the present study it was observed that root induction and development is strongly influenced by two critical factors i.e. auxin type and concentration. Globally, IBA is the most effective and most widely used auxin for root induction, elongation and root hair proliferation efficiency followed by NAA and lastly by IAA. This result is in conformity to the finding of Han et al. ${ }^{5}$ Who reported that the application of auxin, particularly IBA, is one of the most common and effective means to enhance rooting of cultures. The superiority of IBA over NAA and IAA in root development parameters evaluated in the present study has been reported in several woody and non woody species. ${ }^{6-7}$ The superior effects of IBA on root elongation compared to NAA might be due to several factors; such as IBA's preferential uptake, transport, metabolization and subsequent gene activation. ${ }^{8}$ Furthermore, more energy may be needed by the explants to convert the absorbed synthetic NAA from the medium to a natural form of auxin before being used by the explants. Consequently, additional energy would be used that might have eventually led to insufficient energy needed for cell growth and development. This suggestion ties with the work of Zolman et al., ${ }^{9}$ who demonstrated that energy is needed for converting NAA into IAA, hence, reducing efficiency of NAA in root elongation. This condition could likely explain the low efficiency in root induction on explants placed in MS medium supplemented with NAA in the present study. Similarly, different concentrations of IBA showed significant differences in the rate of root emergence. With regards to the superiority of IBA over IAA, it has been explained that the rooting efficacy of IBA is firstly due to the fact that during media preparation, approximately $40 \%$ of IAA is destroyed by 20 min autoclave. Secondly, IBA is more stable than IAA under various light and temperature conditions, both in solution and in vivo. ${ }^{10}$ This assertion might hold with the results obtained in this study given that this culture was exposed to $16 / 8 \mathrm{~h}$ photoperiod. More so, differences in transport, uptake, or metabolism might also contribute to the superior activity of IBA over IAA. ${ }^{11}$

\section{Conclusion}

Ensuring optimum development of the root system of in vitro plantlets is a giant step towards guaranteeing an efficient acclimatization process. Though auxin is a plant growth regulator known to optimize rhizogenesis in in vitro plants, the type and concentration of auxin needed to induce and improve root development is species dependent. In the case of in vitro oil palm plantlets derived from direct organogenesis of mature zygotic embryos, rhizogenesis could be optimized by supplementing MS medium with $1.5 \mathrm{mg} \mathrm{L-}{ }^{1}$ IBA. Actually $71.7 \%$ of rooted seedlings survived acclimatization and have been transplanted to the field. In perspective, their growth parameters shall be assessed with special attention on their flowers and fruits morphology to determine whether they are mantled or not when they get to reproductive maturity. ${ }^{12,13}$

\section{Acknowledgements}

The authors are appreciative to the selection and amelioration unit of the Specialized Centre for Oil palm Research (CEREPAH) La Dibamba, Cameroon for preparation of seeds. Special thanks to the tissue culture laboratory of African Centre for Research on plantain and banana (CARCAB) Njombe, Cameroon for reagents and technical support.

\section{Conflict of interest}

The author declares there is no conflict of interest.

\section{References}

1. Norsazwan MG, Puteh AB, Rafii MG. Oil palm (Elaeis guineensis) seed dormancy type and germination pattern. Seed science and technology. 2006;44(1):15-26

2. Corley RHV, Tinker PB. The Oil Palm. $4^{\text {th }}$ ed. UK: Blackwell Publishing Company; 2003; 56 p.

3. Ansar Ali, Touqeer Ahmad, Nadeem Akhtar Abbasi, et al. Effect of different concentrations of auxins on in vitro rooting of olive cultivar 'moraiolo' Pakistan Journal of Botany. 2009;41(3):1223-1231.

4. Ling APK, Tan KP, Hussein S. Comparative effects of plant growth regulators on leaf and stem explants of Labisi apumila var. alata. $J$ Zhejiang Univ Sci B. 2013;14(7):621-631.

5. Han H, Zhang S, Sun X. A review on the molecular mechanism of plants modulated by auxin. African Journal of Biotechnology 2009;8(3):348 353.

6. Mialoundama F, Avana ML, Youmbi E, et al. Vegetative propagation of Dacryodes edulis (G. Don) H.J. Lam by marcots cuttings and micropropagation. Forests, Trees and Livelihoods. 2002;12(1-2):85-96.

7. Jimenez VM. Involvement of plant hormones and plant growth regulators on in vitro embryogenesis. Plant Growth Regulation. 2005;47(2-3):97110 .

8. Ludwig-Müller J. Indole-3-butyric acid in plant growth and development. Plant Growth Regulation. 2000;32(2-3):219-230.

9. Z Zolman BK, Martinez N, Millius A, et al. Identification and characterization of Arabidopsis indole-3-butyric acid response mutants detective in novel peroxisomal enzymes. Genetics. 2008;180(1):237-251.

10. Nissen SJ, Sutter EG. Stability of IAA and IBA in nutrient medium of several tissue culture procedures. Horticultural Science. 1990;25:800 802.

11. Epstein E, Ludwig-Müller J. Indole-3-butyric acid in plants: occurrence, synthesis, metabolism, and transport. Physiologiaplantarum.1993;88(2):382-389.

12. Jones LH. Propagation of clonal palms by tissue culture. Oil Palm News.1974;17:1-8.

13. Tabi MK, Tonfack LB, Ntsomboh NG, et al. Mature zygotic embryo rescue improves in vitro germination and seedling production in high value oil palm (Elaeis guineensis Jacq.) cultivars. Industrial crops \& product. 2016;94(30):445-453. 